\title{
Reproducibility of protected brush catheter specimen cultures in critically ill patients with suspected nosocomial pneumonia
}

\author{
GEORGE A FOX MD FRCPC, DAVID J LEASA MD FRCPC, WILLIAM J SIBBALD MD FRCPC FACP, \\ DAVID G MCCORMACK MD FRCPC \\ Victoria Hospital and University Hospital, London, Ontario
}

\begin{abstract}
Ga Fox, DJ Leasa, WJ Sibbald, DG MCCormack. Reproducibility of protected brush catheter specimen cultures in critically ill patients with suspected nosocomial pneumonia. Can Respir J 1995;2(3):173-178.
\end{abstract}

OBJEcTIVE: To determine the reproducibility of two protected brush catheter (PBC) specimens obtained during the same bronchoscopy in critically ill patients with suspected ventilator associated pneumonia.

DESIGN: Prospective, observational study.

SeTting: Two university-affiliated multidisciplinary intensive care units with a combined total of 50 beds.

Patients: A total of 75 (50 male, 25 female) patients with 84 episodes of suspected ventilator associated pneumonia were studied between January 1, 1991 and June 30, 1992. Age was $60.7 \pm 1.9$ (mean \pm SEM) years, and mean

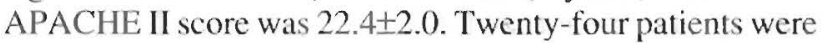
admitted from various medical services, 19 from surgical services including the operating room, 16 with central nervous system disease and 16 following multiple traumi. Twenty patients were transferred directly to the intensive care unit from peripheral hospitals.

INTERVENTIONS: All patients had lower respiratory tract secretions obtained for culture by both aspiration through the endotracheal tube (tracheal aspirates) and flexible bronchoscopy, with separate samples obtained by two PBCs (PBC-A and PBC-B).

MAIN RESULTS: The overall proportion of agreement between the results of the two PBC specimens was 0.928 , with a calculated kappa statistic $(\kappa)=0.853(\mathrm{P}<0.01$ versus $\kappa=0.4,95 \%$ CL $0.692,1.014)$ indicating excellent agreement between the two specimens. Both PBC specimens had significant (ie, more than $10^{3}$ colony-forming units/mL) growth (positive/positive) in 33 cases, nonsignificant growth in 45 cases (negative/negative) and discordant results in six (positive/negative, $\mathrm{n}=3$ or negative/positive, $n=3)$. There was a significant relationship $(P<0.05)$ between the concurrent use of antibiotics and a negative $\mathrm{PBC}$ result. However, after exclusion of patients on antibiotics, the overall proportion of agreement between the two PBCs was 0.94 with $\mathrm{K}=0.875(\mathrm{P}<0.0$ I versus $\mathrm{K}=0.4,95 \% \mathrm{CL} 0.721$, 1.029), which also indicates excellent agreement between the two tests.

Conclusions: Although discordant results were observed in $7.2 \%$ cases, the overall reproducibility of the $\mathrm{PBC}$ results appears to be high. The significant relationship between concurrent antibiotic use and a negative PBC result is of concern clinically since many patients are being treated with antibiotics at the time of bronchoscopy. Therefore, when the diagnosis of nosocomial pneumonia in critically ill patients is established, the PBC result should be considered only in association with all the other clinical data, particularly in patients receiving concurrent antibiotics. (Pour le résumć. wir page 174)

Key Words: Kappa shatistic, Mechanical vemilation. Nosocomial

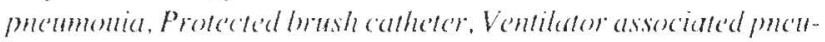
moninl

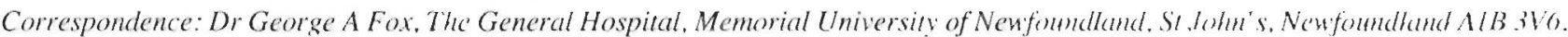
Telephone709-737-5191,Fux70)-737-7052,e-mail gfox@kean.ucs.mum.cu 


\section{Reproductibilité des cultures de spécimens obtenus par brossage protégé chez des patients des soins intensifs avec une pneumonie noso- comiale suspectée}

OB.JEctrF : Déterminer la reproductibilité de la culture de deux spécimens obtenus par brossage protégé (BP) au cours (l'une même bronchoscopie chez des patients des soins intensifs chez qui l'on suspecte une pneumonie associée à la ventilation mécanique.

MoDÈLE : Étude d'observation, prospective.

CONTEXTE : Deux unités de soins intensifs multidisciplinaires aftiliées à une université représentant un total de 50 lits. Patients : Un total de 75 (50 hommes, 25 femmes) paticnts avec 84 épisodes de pneumonie suspectée associée au respirateur ont été étudiés entre le $1^{\mathrm{er}}$ janvier 1991 et le 30 juin 1992. L'âge de ces patients était de 60,7士1,9 (moyenne \pm erreur type de la moyenne) ans et to score moyen

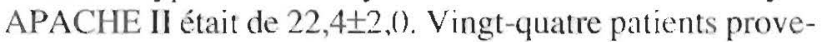
naient de services médicaux variés, 19 du service de chirurgie y compris la salle d'opération, 16 souffraient de pathologies du système nerveux central et 16 avaient été admis à la suite de traumatismes multiples. Vingt patients avaient été directement transférés des hôpitaux périphériques vers l'unité de soins intensifs.

INTER VENTIONS : Chez tous les patients, on a prélevé des sécrétions bronchiques pour les mettre en culture, par la sonde endotrachéale (aspirations trachéales) et par bronchoscopie souple, avec deux échantillons distincts obtenus par brossages protégés (BP-A et BP-B).
Principaux Résultats : La proportion globale de concordance des résultats des deux spécimens obtenus par BP était de 0,928 avec une statistique kappa calculée $(\kappa)=0,853$ $(\mathrm{P}<0,01$ par rapport à $\mathrm{K}=0,4$, intervalle de confiance à $95 \%$ 0,692-1,014) démontrant une concordance excellente entre les deux spécimens. Les deux spécimens obtenus par BP ont révélé une croissance significative (plus de $10^{3}$ unités formant colonies/ml) dans 33 cas (positif-positif), une croissance non significative (négative-négative) dans 45 cas et des résultats discordants dans six cas (positif-négatif, $\mathrm{n}=3$ ou négatif-positif, $\mathrm{n}=3$ ). On a observé une relation significative $(P<0,05)$ entre l'utilisation concomitante d'antibiotiques et un résultat négatif du BP. Cependant, après avoir exclu de l'étude les patients sous antibiotiques, la proportion globale de concordance entre les deux spécimens obtenus par BP était de 0,94 avec $\kappa=0,875$ ( $\mathrm{P}<0,01$ par rapport à $\kappa=0,4$, intervalle de confiance à $95 \% 0,721-1,029)$, ce qui indique également une concordance excellente entre les deux tests.

Conclusions : Bien que des résultats discordants aient été observés dans 7,2\% des cas, la reproductibilité globale des résultats du BP semble élevée. La relation significative entre I'utilisation concomitante d'antibiotiques et un résultat du BP négatif semble importante cliniquement puisque de nombreux patients sont sous antibiotiques au moment de la bronchoscopie. Donc, lorsque le diagnostic de pneumonie nosocomiale a été posé chez des patients des soins intensifs, le résultat du BP devrait seulement être interprété en fonction de toutes les autres données cliniques, surtout chez les patients qui sont déjà sous traitement antibiotique.
E STABLISHING THE CLINICAI. 1)IAGNOSIS OF PNEUMONIA in mechanically ventilated patients is both inaccurate and often difficult. Oropharyngeal and endorracheal tube colonization with pathogenic bacteria occurs within $24 \mathrm{~h}$ of intubation and decreases the reliability of expectorated or aspirated tracheal secretions (1). Furthermore, critically ill patients often have pulmonary infiltrates, fever and leukocytosis due to other conditions (pulmonary embolism, atelectasis, pulmonary edema, etc), which complicates the diagnosis of pneumonia.

Fibreoptic bronchoscopy has been used extensively in intubated patients with suspected pneumonia to obtain samples of lower respiratory tract secretions for bacterial culture (2-4). The development of the protected brush catheter (PBC) has further enhanced the usefulness of bronchoscopy in the diagnosis of nosocomial pneumonia (5-9). In addition, many investigators (10-12) belicve that the PBC used in conjunction with quantitative bacterial culture techniques improves the accuracy of the diagnosis of ventilator associated pneumonia.

The reliability or precision of a diagnostic test depends on how close repeated measurements of a stable phenomenon are to each other (13). To date, the reliability of the PBC technique remains uncertain in the clinical setting. There has been limited experience with collecting multiple PBC specimens from the same individual to determine the repro- ducibility of this technique (14-16). Marquette et al (15) demonstrated excellent qualitative reproducibility of the $\mathrm{PBC}$ technique; however, quantitative cultures varied by more than $1 \log _{10}$ in over half the patients studied, and the presence or absence of pneumonia (based on the critical 'cutoff' of greater than $10^{3}$ colony-forming units [CFU $] / \mathrm{mL}$ ) differed in about $14 \%$ of patients. Similarly, Timsit et al (16) observed discordant results between two PBC specimens in about $17 \%$ of patients with suspected ventilator acquired pneumonia. We previously collected two PBC specimens during bronchoscopy in 48 critically ill patients with 53 episodes of suspected ventilator acquired pneumonia (14) and noted a discrepancy between the two brush specimens in $7.5 \%$ of cases. In the present paper, we describe the completed data of this study on 75 patients with 84 episodes of suspected ventilator acquired pneumonia in which we col lected two sequential PBC specimens alt bronchoscopy.

\section{PATIENTS AND METHODS}

The study protocol was approved by the human investigation committee at the University of Western Ontario.

Patient selection: Data were collected during 84 episodes of suspected nosocomial pneumonia occurring in 75 critically ill patients between January 1, 1991 and June 30, 1992. Patients were enrolled from two multidisciplinary intensive care units at the University of Western Ontario with a com- 
bined total of 50 beds and approximately 2200 annual admissions. The clinical diagnosis of nosocomial pneumonia was suspected in patients receiving mechanical ventilation for more than $48 \mathrm{~h}$ if they developed a new pulmonary infiltrate that persisted longer than $24 \mathrm{~h}$, developed macroscopically purulent tracheal secretions, and either leukocytosis (white blood cell count greater than $11,000 / \mathrm{mm}^{3}$ ) or elevated temperature (greater than $38.3^{\circ} \mathrm{C}$ ). Patients were excluded if they met any of the following criteria: clinical condition that did not permit flexible bronchoscopy; diagnosis of pneumonia upon admission to the intensive care unit; immunocompromised condition (organ transplant, hematological malignancy, humoral or cellular immune deficiency and patients receiving more than $0.5 \mathrm{mg} / \mathrm{kg} /$ day of prednisone or its equivalent); or age less than 18 years.

All patients were ventilated with a Bird (Bird Products Corporation, Califomia), Veolar (Hamilton Medical, Nevada) or a Puritan-Bennett 7200 (Puritan-Bennett Corporation, California) ventilator through an orotracheal, nasotracheal or tracheostomy tube. The ventilator tubing (Marquest Medical Products, Colorado) was changed every $48 \mathrm{~h}$ according 10 routine protocol. Tracheobronchial suctioning, chest physiotherapy and drainage of condensate from the ventilator tubing were performed every $3 \mathrm{~h}$ or more frequently if it was deemed necessary by the attending staff.

Experimental protocol: On entry into the study, the patient's hospital chart was reviewed and the following variables recorded: age, sex, underlying medical illnesses, date of hospital and intensive care unit admission, date of intubation, APACHE II score (17) and antibiotics used within $48 \mathrm{~h}$ before bronchoscopy. Specific physiological variables (ie, Acute Physiologic Score $(17,18)$ and a radiographic assessment (radiographic score) $(19,20)$ were recorded on the day of bronchoscopy.

All potentially eligible patients were reviewed on a daily basis for the signs and symptoms of pneumonia described above. Once these signs developed and persisted more than $24 \mathrm{~h}$, the patient (if awake) or the next of kin were approached for possible enrolment into the study. After informed consent was given, lower respiratory tract secretions were obtained for culture from all patients within $12 \mathrm{~h}$ of inclusion into the study and within $36 \mathrm{~h}$ after the diagnosis of pneumonia was suspected. Bacteriological samples were collected by both aspiration through the endotracheal tube (tracheal aspirates) and flexible bronchoscopy, with separate samples obtained by two PBCs (PBC-A and PBC-B). Tracheal aspirates were obtained immediately before bronchoscopy from all cases by an aseptic technique using deep suctioning via the endotracheal tube and collected in a sterile suction trap.

In preparation for bronchoscopy, all patients were premedicated with intravenous diazepam (5 to $10 \mathrm{mg}$ ) or midazelam ( 2.5 to $5 \mathrm{mg}$ ) with or without fentanyl ( 50 to $100 \mu \mathrm{g}$ ). Topical xylocaine ( 1 to $2 \%$ ) was used minimally for local anesthesia only when patients continued to cough despite intravenous sedation. Arterial oxygen saturation and cardiac rhythm were continuously monitored throughout the procedure with a pulse oximeter (SpaceLabs, Washington; Hewlett

\section{TABLE 1}

Demographic data of patients with suspected ventilator associated pneumonia

\begin{tabular}{lccc}
\hline & $+l+(n=33)$ & $-1-(n=45)$ & $+1-(n=6)$ \\
\hline Age (years) & $53.7 \pm 3.6$ & $66.6 \pm 1.8$ & $60.8 \pm 9.6$ \\
APACHE II score & $21.0 \pm 1.3$ & $22.9 \pm 0.9$ & $26.2 \pm 3.4$ \\
$\begin{array}{l}\text { Intubation-bronchoscopy } \\
\text { interval (days) }\end{array}$ & $11.5 \pm 2.4$ & $17.9 \pm 3.3$ & $6.2 \pm 2.0$ \\
$\begin{array}{l}\text { Antibiotics within } 48 \mathrm{~h} \\
\text { of bronchoscopy }\end{array}$ & $11(33.3 \%)$ & $30(66.7 \%)$ & $5(83.3 \%)$ \\
$\begin{array}{l}\text { Underlying illness } \\
\quad \text { Medical }\end{array}$ & 11 & & \\
Surgical & 6 & 16 & 1 \\
$\quad$ CNS & 7 & 8 & $?$ \\
$\quad$ Trauma & 9 & 9 & 2 \\
\hline
\end{tabular}

$+1+$ Both protected brush catheter $(P C B)$ specimens $>10^{3}$ colony forming units (CFU) $/ \mathrm{mL} ;-1-$ Both PBC specimens $<10^{3} \mathrm{CFU} / \mathrm{mL}$; $+1-$ one PBC specimen $>10^{3} \mathrm{CFU} / \mathrm{mL}$, one specimen $<10^{3} \mathrm{CFU} / \mathrm{mL}$. Data are mean $\pm S E M$

Packard, Massachusetts) and cardiac monitor (SpaceLabs; Hewlett Packard). With the fraction of inspired oxygen adjusted to 1.0, the flexible fibreoptic bronchoscope (Pentax model $\mathrm{FB} 19 \mathrm{H}$ ) was introduced into the endotracheal tube through a special adapter (Rusch-Kernen, Germany) allowing simultaneous mechanical ventilation and the maintenance of positive airway pressure. The bronchoscope was advanced into the bronchial orifice of the involved pulmonary segment that had been identified radiographically. Telc... scoping PBCs (Mill-Rose; Instrumed) with distal plugs were inserted through the inner suction channel of the bronchoscope. Once in the involved bronchopulmonary segment, the dissolvable cellulose plug was dislodged and the brush advanced under visual guidance into the area of suspected pneumonia. After the involved segment was brushed, the brush (PBC-A) was withdrawn into the protective sheath and the entire catheter was removed from the bronchoscope (19). In each patient, a second protected brush specimen (PBC-B) was immediately obtained from the same bronchopulmontry segment by an identical technique.

To minimize potential contamination of the bronchoscope, suctioning was kept to a minimum throughout the procedure. After withdrawal, the outcr catheter was immediately cleansed with an alcohol swab and severed with sterile scissors. The distal portion of the inner telescoping catheter was advanced, cleansed and cut in a similar manner. The brush wire was then advanced and cut with sterile scissors into a sterile glass vial containing $1.0 \mathrm{~mL}$ of lactated sterile saline solution.

Between cases the bronchoscope was cleaned according to routine protocol. Briefly, the bronchoscope is dismantled and cleaned with a brush and soap and water, then soaked in Cidex (Johnson and Johnson) for 30 mins before being rinsed with sterile water.

Bacteriological assessment: After collction, specimens were immediately transported to the microbiology department, where tracheal aspirates were Gram stained and cul- 
TABLE 2

Clinical features of patients with suspected ventilator associated pneumonia

\begin{tabular}{lccc}
\hline & $+1+(\mathrm{n}=33)$ & $-1-(\mathrm{n}=45)$ & $+1-(\mathrm{n}=6)$ \\
\hline Temperature $\left({ }^{\circ} \mathrm{C}\right)$ & $38.1 \pm 0.19$ & $38.0 \pm 0.33$ & $38.1 \pm 0.21$ \\
Purulent sputum & 33 & 45 & 6 \\
White blood cells $/ \mathrm{mm}^{3}$ & $14.0 \pm 1.1$ & $16.7 \pm 1.6$ & $15.1 \pm 1.5$ \\
Chest $x$-ray score & $5.1 \pm 0.4$ & $5.2 \pm 0.3$ & $6.1 \pm 1.2$ \\
\hline
\end{tabular}

$+1+$ Both protected brush catheter (PCB) specimens $>10^{3}$ colony forming units (CFU) $/ \mathrm{mL}^{-}-1-$ Both PBC specimens $<10^{3} \mathrm{CFU} / \mathrm{mL}$; +1one PBC specimen $>10^{3} \mathrm{CFU} / \mathrm{mL}$, one specimen $<10^{3} \mathrm{CFU} / \mathrm{mL}$. Data are mean \pm SEM

tured un MacConkey agar, 5\% horse blood agar and chocolate agar. Identification of pathogenic bacteria and antibiotic sensitivities were determined according to routine laboratory protocol.

Specimen vials containing the protected brush tips were placed in a vortex mixer for $60 \mathrm{~s}$ to suspend all material from the brush. After Gram staining, two serial 100-fold dilutions were performed and $0.1 \mathrm{~mL}$ of each dilution was plated on MacConkey agar, $5 \%$ horse blood agar and chocolate agar for quantitative culture. Cultures were considered positive if more than $10^{3} \mathrm{CFU} / \mathrm{mL}$ of one or more potentially pathogenic bacteria were isolated.

Statistical analysis: All data are presented as mean \pm SEM. Qualitative comparisons were performed with $\chi^{2}=0.05$ statistical analysis. Agreement between the first (PBC-A) and second $(\mathrm{PBC}-\mathrm{B})$ culture results was assessed by calculating the kappa statistic ( $\kappa)(21)$.

\section{RESULTS}

Eighty-four episodes of clinically suspected pneumonia were identified in 75 patients. The demographic characteristics of these patients are presented in Table 1. There were 50 males and 25 females with a mean age of $60.7 \pm 1.9$ years. Twenty-four patients were admitted from various medical services, 19 from surgical services including the operating room, 16 with central nervous system disease and 16 following multiple trauma. Twenty patients were transferred directly to the intensive care unit from peripheral hospitals. The mean APACHE II score at the time of intensive care unit admission was $22.4 \pm 0.8$. Patients were ventilated for an iverage of $14.5 \pm 2.0$ days before the development of clinical pneumonia.

No specific clinical features could be identified that would differentiate patients with pneumonia (based on significant PBC specimen culture) from those without pneumonia (nonsignificant PBC specimen culture). Specifically, there were no differences in temperature, white blood cell count, sputum purulence or radiographic infiltrates among the three groups (Table 2).

Bacteriological results: In all patients, semiquantitative cultures of tracheal aspirates were positive (Table 3). In nine of the 84 cases, the tracheal aspirate specimens grew multiple organisms. The bacteriological criterion of more than $10^{3}$ $\mathrm{CFU} / \mathrm{mL}$ of potentially pathogenic bacteria was used to iden-

\section{TABLE 3}

Bacteriology of tracheal aspirate (TA) and significant protected brush catheter (PBC) cultures

\begin{tabular}{lrc}
\hline Microorganism & TA & PBC \\
\hline Streptococcus pneumoniae & 11 & 12 \\
Staphylococcus aureus & 14 & 16 \\
Neisseria mucosa & 1 & 2 \\
Haemophilus influenzae & 14 & 18 \\
Pseudomonas aeruginosa & $? 0$ & 18 \\
Escherichia coli & 9 & 7 \\
Klebsiella pneumoniae & 7 & 7 \\
Proteus mirabilis & 3 & 2 \\
Enterobacter cloacae & 7 & 2 \\
Xanthomona maltophilia & 4 & \\
Serratia marcesens & 2 & \\
Acinetobacter species & 1 & \\
Total & 93 & 84
\end{tabular}

PBC specimens were significant if cultures grew more than $10^{3}$ colony-forming units/ $m L$

tify a significant bacterial growth in lower respiratory trict secretions obtained with the PBC. Of the 168 PBC specimens, $72(42.9 \%)$ demonstrated significant bacterial growlh, while $96(57.1 \%)$ were considered nonsignificant. In 33 cases, both $\mathrm{PBC}$ specimens had significant growth (positive/positive), in 45 cases, both had nonsignificant growth (negative/negative), and culture results were discordant in six (positive/negative, $n=3$ or negative/positive, $n=3$ ).

Quantitative culture of the PBC specimen grew Grampositive cocci in 13, Gram-negative bacilli in 25 and Gramnegative diplococci in one (Table 3 ).

Of six patients with discordant results, both $\mathrm{PBC}-\mathrm{A}$ and PBC-B grew the same organism in four. The quantitative cultures in these four cases differed by $1 \log _{10}$ above and below the critical cutoff of greater than $10^{3} \mathrm{CFU} / \mathrm{mL}$. In the remaining two cases, the first PBC specimen was significant (ic. greater than $10^{3} \mathrm{CFU} / \mathrm{mL}$ ), while the second specimen was sterile (Table 4). The overall proportion of agrecment between the two PBC specimens was 0.928 (Table 5) with at calculated kappa statistic of $\kappa=0.853(\mathrm{P}<0.0 \mathrm{I}$ versus $\kappa=() .4$. $95 \%$ CL $0.692,1.014)$ indicating excellent agreement between the tests.

In $46(54.7 \%)$ cases of pneumonia, antibiotics had been administered within $48 \mathrm{~h}$ before bronchoscopy. The use of antibiotics was significantly $(\mathrm{P}<0.05)$ associated with a nonsignificant $\mathrm{PBC}$ result (Table 1). Of the 33 patients with positive/positive PBC results, only 11 had received antibiotics, whereas 35 of the 51 patients with either negative/negative, positive/negative or negative/positive PBC results had been on antibiotics before bronchoscopy. Of these 46 cases receiving antibiotics, 11 were positive/positive, 30 were negative/negative and four were positive/negative. The overall proportion of agreement (0.94) and the kappa stallistic were recalculated using the 38 cases that did not receive antibiotics (Table 5). Thus, excluding prior antibiotics. $\kappa=0.875(\mathrm{P}<0.01$ versus $\kappa=0.4,95 \% \mathrm{CL} 0.721,1.029)$ also indicates excellent agreement between the two tests. 


\section{TABLE 4}

Bacteriology of six patients with discordant protected brush catheter $(\mathrm{PBC})$ results

\begin{tabular}{|c|c|c|c|c|}
\hline \multirow[b]{2}{*}{ Patient } & \multicolumn{2}{|c|}{ PBC A } & \multicolumn{2}{|c|}{ PBC B } \\
\hline & $\mathrm{CFU} / \mathrm{mL}$ & Organism & $\mathrm{CFU} / \mathrm{mL}$ & Organism \\
\hline 1 & $2.3 \times 10^{2}$ & $\begin{array}{c}\text { Pseudomonas } \\
\text { aeruginosa }\end{array}$ & $2.0 \times 10^{3}$ & $P$ aeruginosa \\
\hline $2^{*}$ & $4.0 \times 10^{2}$ & $\begin{array}{l}\text { Staphylococcus } \\
\text { aureus }\end{array}$ & $3.0 \times 10^{3}$ & $S$ aureus \\
\hline 3 & $1.1 \times 10^{3}$ & $\begin{array}{l}\text { Haemophilus } \\
\text { influenzae }\end{array}$ & 0 & \\
\hline 4 & $2.3 \times 10^{3}$ & $P$ aeruginosa & 0 & \\
\hline 5 & $4.0 \times 10^{2}$ & $P$ aeruginosa & $1.3 \times 10^{3}$ & $P$ aeruginosa \\
\hline 6 & $6.2 \times 10^{2}$ & $P$ aeruginosa & $1.4 \times 10^{3}$ & Paeruginosa \\
\hline
\end{tabular}

"Did not receive antibiotics before bronchoscopy. CFU Colony-forming units

\section{DISCUSSION}

Nosocomial pneumonia continues to be a significant problem in the critically ill patient. As a result of inaccurate clinical features and limited acceptance of invasive diagnostic procedures (22) the diagnosis of pneumonia in mechanically ventilated patients is a common problem $(11,23,24)$. Our data concur with existing literature (11.19,24-27) and demonstrate that, based on clinical features alone, the diagnosis of ventilator associated pneumonial is unreliable compared with the PBC as the 'gold standard'. We have also shown that the PBC used to obtain lower respiratory tract secretions at the time of bronchoscopy is associated with a high degree of reproducibility and interobserver agreement. However, the concurrent use of antibiotics before bronchoscopy may decrease the reliability of the PBC in the clinical setting.

If $\mathrm{PBC}$ is assumed to be the gold standard for diagnosing nosocomial pneumonia in critically ill ventilated patients, we would have overdiagnosed ventilator associated pneumonia in the majority of our study patients on the basis of tracheal aspirates and clinical features. Similarly, Fagon et al (19) obtained PBC specimens in 162 cases of suspected ventilator associated pneumonia and obtained significant bacteriological results in only $35 \%$. In our study, significant PBC cultures were obtained in only 72 of 168 (42.9\%) specimens. When we examined the two groups separately, we could not identify any distinguishing clinical features between them. These results reinforce the diagnostic dilemma faced by clinicians in the critical care setting when they try to establish the diagnosis of ventilator associated pneumonia. This is particuIarly important where inappropriate antibiotic therapy in patients without pneumonia may lead to added morbidity and health care costs.

Since the role of the $\mathrm{PBC}$ in clinical practice is to guide antibiotic therapy in patients with nosocomial pneumonia, irreprofucible or unreliable results may have a detrimental impact on patient outcome. This is the largest series to date examining the reproducibility of $\mathrm{PBC}$ results in patients with suspected ventilator acquired pneumonia. We observed an overall proportion of agreement between the two PBC speci-
TABLE 5

Reliability of protected brush catheter (PBC) results

A. All patients

\begin{tabular}{ll|r|r|r}
\multicolumn{3}{c}{} & \multicolumn{3}{c}{ Positive } & \multicolumn{1}{c}{ Negative } \\
\cline { 3 - 4 } PBC-B & Positive & 33 & 3 & 36 \\
\cline { 3 - 4 } & Negative & 3 & 45 & 48 \\
\cline { 3 - 4 } & & 36 & 48 & 84
\end{tabular}

\begin{tabular}{|c|c|c|c|c|}
\hline \multicolumn{5}{|c|}{ B. Patients not receiving antibiotics } \\
\hline \multirow{4}{*}{ PBC-B } & \multirow{4}{*}{$\begin{array}{l}\text { Positive } \\
\text { Negative }\end{array}$} & Positive & Negative & \\
\hline & & 22 & 1 & 23 \\
\hline & & 1 & 15 & 16 \\
\hline & & 23 & 16 & 39 \\
\hline
\end{tabular}

mens of 0.928 for all specimens and 0.94 for specimens in patients not treated with antibiotics (Table 5). The kappa statistic for interobserver agreement indicates excellent agreement between the two PBC specimens. Our results are in contrast to those of others $(16,28)$ in that we only observed discordant results in six (7.2\%) cases. We believe, however, that the kappa statistic for interobserver agreement is a much more rigorous statistical test (21) than simply measuring the rates of discordance $(15,16)$, because the kappa statistic determines the amount of agreement observed in relation to that expected on the basis of chance alone.

The observed discrepancy between the two brushes in our study may be the result of either sampling error or biological variation in the bacterial population (13). Potential sources of sampling error may be secondary to technical factors (ie, catheter placement, suctioning of tracheal secretions through the bronchoscope, the use of topical anesthetics) or observer variation (ie, laboratory personnel). In an effort to circumvent these potential errors all bronchoscopic procedures were performed by three individuals. The PBC sample was obtained only when endobronchial pus was seen and the same technique was used for both specimens. Furthermore, topical anesthetics were used sparingly and suctioning was minimized throughout the procedure. Biological variation may be due to the concurrent use of antibiotics, presence or absence of comorbid disease and the presence of bacterial colonization. Furthermore, bacteriological counts may vary within the local melieu of the lower respiratory tract $(29,30)$.

We observed a significant $(\mathrm{P}<0.05)$ and disproportionately high frequency of antibiotic use in patients with negative/negative, positive/negative or negative/positive $\mathrm{PBC}$ results (Table 1). Forty-six of 84 patients had received antibiotics within $48 \mathrm{~h}$ of bronchoscopy, of whom 35 had a nonsignificant $\mathrm{PBC}$ result and 11 had significant $\mathrm{PBC}$ results (positive/positive). Although not conclusive, these data raise the possibility that prior or concurrent antibiotic therapy may be associated with nonsignificant PBC results. Unfortunately, in this study we were unable to determine whether this represents a true false-negative result since tissue samples (the ultimate gold standard) were not collected. 


\section{CONCLUSIONS}

Even though we observed discordant results in $7.2 \%$ of our patients the overall reproducibility of the PBC results appears to be high with excellent agreement between the two tests. More important, however, we noted a significant relittionship between the concurrent use of antibiotics and nonsignificant $\mathrm{PBC}$ results. Therefore, although we believe that the $\mathrm{PBC}$ is a useful test, we emphasize that when ventilator associated pneumonia is diagnosed, the PBC results should be considered along with other clinical information, particularly in patients receiving antibiotics. In addition, these data add to the recent debate over the use of invasive versus noninvasive diagnostic procedures in this setting, and should stimulate future research on the effects of concurrent intibiotic use and the reliability of PBC specimens.

ACKNOWLEDGEMENTS: The authors acknowledge the contribution of the attending intensive care unit staff and nurses as well as the microbiology laboratories at both Victoria and University Hospitals, London, Ontario.

\section{REFERENCES}

1. Barrett-Connor $\mathrm{E}$. The nonvalue of sputum culture in the diagnosis of pneumococcal pneumonia. Am Rev Respir Dis 1971;103:845-8.

2. Flatauer FE, Chabalko JJ, Wolinsky E. Fiberoptic bronchoscopy in bacteriologic assessment of lower respiratory tract secretions. JAMA 1980;244:2427-9.

3. Fulkerson WJ. Fiberoptic bronchoscopy. N EngI J Med 1984;3 I I:5 I I-5.

4. Teague RB, Wallace RJ Jr, Awe RJ. The use of quantitative sterile brush culture and Gram stain analysis in the diagnosis of lower respiratory tract infection. Chest 1981;79:157-61.

5. Wimberley N, Faling LJ, Bartlett JG. A fiberoptic bronchoscopy technique to obtain uncontaminated lower airway secretions for bacterial culture. Am Rev Respir Dis 1979; 1 19:337-43

0. Wimberley NW, Bass JB Jr, Boyd BW, Kirkpatrick MB, Serio RA, Pollock HM. Use of a bronchoscopic protected catheter brush for the diagnosis of pulmonary infections. Chest 1982;81:556-62.

7. Hayes DA, McCarthy LC, Friedman M. Evaluation of two bronchofiberscopic methods of culturing the lower respiratory tract. Am Rev Respir Dis 1980;122:319-23.

8. Joshi JH, Wang KP, De Jongh CA, Newman KA, Wiernik PH, Schimpff SC. A comparative evaluation of two fiberoptic bronchoscopy catheters: the plugged telescoping catheter versts the single sheathed nonplugged catheter. Am Rev Respir Dis 1982;126:860-3.

9. Bordelon JY Jr, Legrand P, Gewin WC, Sanders CV. The telescoping plugged catheter in suspected anaerobic infections. Am Rev Respir Dis 1983;128:465-8.

10. Moser KM, Maurer J, Jassy L, et al. Sensitivity, specificity, and risk of diagnostic procedures in a canine model of Streptococcus pneumoniae pneumonia. Am Rev Respir Dis $1982 ; 125: 436-42$.

11. Fagon JY, Chastre J, Hance AJ, et al. Detection of nosocomial lung infection in ventilated patients. Am Rev Respir Dis 1988;138:1 10-6.

12. Chastre J, Fagon JY. Invasive diagnostic testing should be routinely used to manage ventilated patients with suspected pneumonia. Am J Respir Crit Care Med 1994;150:570-4.
13. Fletcher RH, Fletcher SW, Wagner EH. Clinical Epidemiology: The Essentials, 2nd edn. Baltimore: Williams \& Wilkins, 1988:246.

I4. Fox GA, Leasa DJ, Sibbald WJ, McCormack DG. Reproducibility of the protected brush catheter: Comparison of two sequential PBCs in patients with ventilator associated pneumonia. Crit Care Med 1992;20:S49. (Abst)

15. Marquette CH, Herengt F, Mathieu D, Saulnier F, Courcol R, Ramon P. Diagnosis of pneumonia in mechanically ventilated patients: repeatability of the protected specimen brush. Am Rev Respir Dis 1993;147:211-4.

16. Timsit JF, Misset B, Francoual S, Goldstein FW, Vaury P, Carlet $\mathbf{J}$. Is protected specimen brush a reproducible method to diagnose ICU-acquired pneumonia. Chest 1993; 104:104-8.

17. Knaus WA, Draper EA, Wagner DP, Zimmerman JE. APACHE II: A severity of disease classification system. Crit Care Med 1985;13:818-29.

18. Durocher A, Saulnier F, Beuscart R, et al. A comparison af three severity score indexes in an evaluation of serious bacterial pneumonia. Intensive Care Med 1988;14:39-43.

14. Fagon JY, Chastre J, Domart Y, et al. Nosocomial pneumonia in patients receiving continuous mechanical ventilation. Am Rev Respir Dis 1989;139:877-84.

20. Weinberg PF, Matthay MA, Webster RO, Roskos KV, Goldstein IM, Murray JF. Biologically active products of complement and acute lung injury in patients with the sepsis syndrome. Am Rev Respir Dis 1984;130:791-6.

21. Fleiss JL. Statistical Methods for Rates and Proportions, 2nd edn. New York: John Wiley \& Sons, 1981:321.

22. Niedermen MS, Torres A, Summer W. Invasive diagnostic testing is not needed routinely to manage suspected ventilator-associated pneumonia. Am J Respir Crit Care Med 1994; 150:565-9.

23. Andrews CP, Coalson JJ, Smith JD, Johanson WG Jr. Diagnosis of nosocomial bacterial pneumonia in acute, diffuse lung injury. Chest 1981;80:254-8.

24. Chastre J, Viau F, Brun P, et al. Prospective evaluation of the protected specimen brush for the diagnosis of pulmonary infections in ventilated patients. Am Rev Respir Dis 1984;130:924-9.

25. Chastre J, Fagon JY, Soler P, et al. Diagnosis of nosocomial bacterial pneumonia in intubated patients undergoing ventilation: comparison of the usefulness of bronchoalveolar lavage and the protected specimen brush. Am J Med 1988;85:499-506.

27. Torres A, De La Bellacasa JP, Rodriguez-Roisin R, De Anta MTJ, Agusti-Vidal A. Diagnostic value of telescoping plugged catheters in mechanically ventilated patients with bacterial pneumonia using the Metras catheter. Am Rev Respir Dis 1988;138:1 17-20.

27. Torres A, Puig de la Bellacasa J, Xaubet A, et al. Diagnostic value of quantitative cultures of bronchoalveolar lavage and telescoping plugged catheters in mechanically ventilated patients with bacterial pneumonia. Am Rev Respir Dis 1989;140:306-10.

28. Marquette CH, Georges H, Wallet F, et al. Diagnostic efficiency of endotracheal aspirates with quantitative bacterial cultures in intubated patients with suspected pneumonia. Am Rev Respir Dis 1993;148:138-44.

29. Baughman RP, Thorpe JE, Rashkin M, Frame PT. Use of the protected specimen brush in patients with endotracheal or tracheostomy tubes. Chest 1987;91:233-6.

30. De Castro FR, Sole VJ, Lafarga CB, Caminero LJ, Gonzalez RB, Manzano AJL. Reliability of the bronchoscopic protected catheter brush in the diagnosis of pneumonia in mechanically ventilated patients. Crit Care Med 1991;19:171-5. 


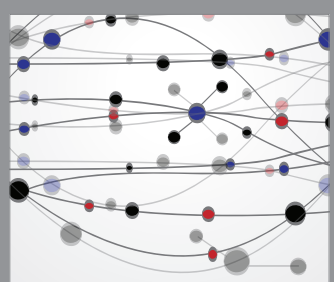

The Scientific World Journal
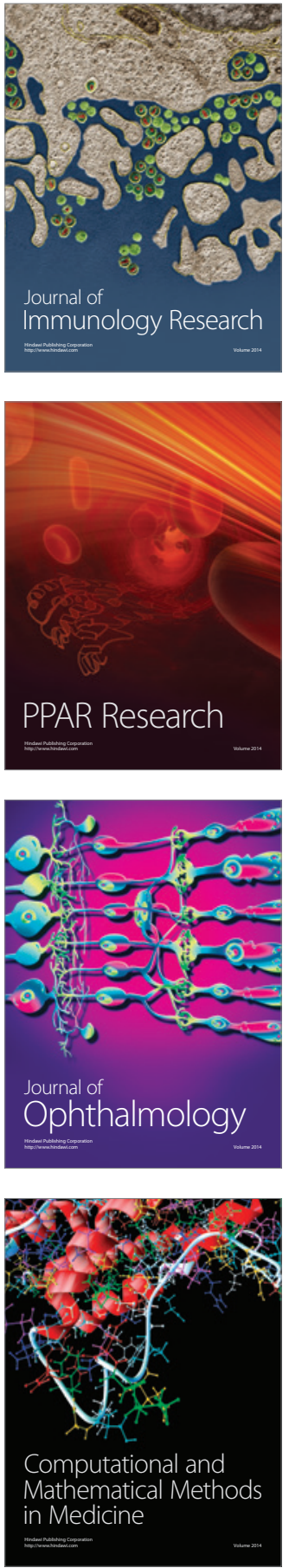

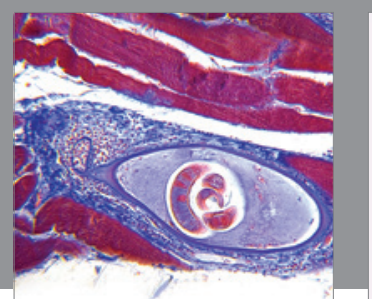

Gastroenterology Research and Practice

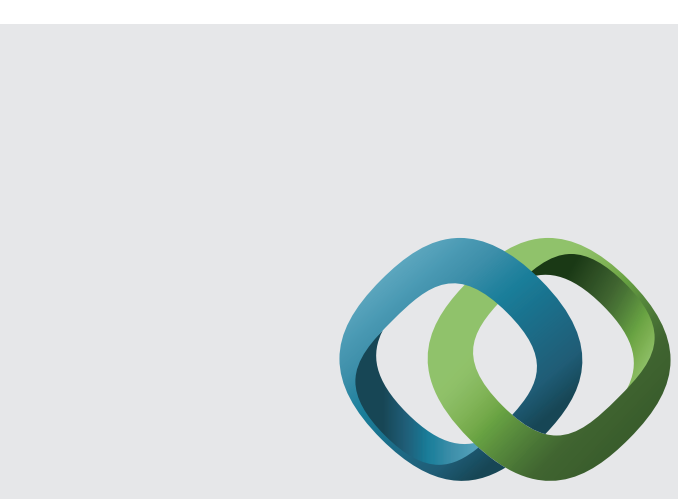

\section{Hindawi}

Submit your manuscripts at

http://www.hindawi.com
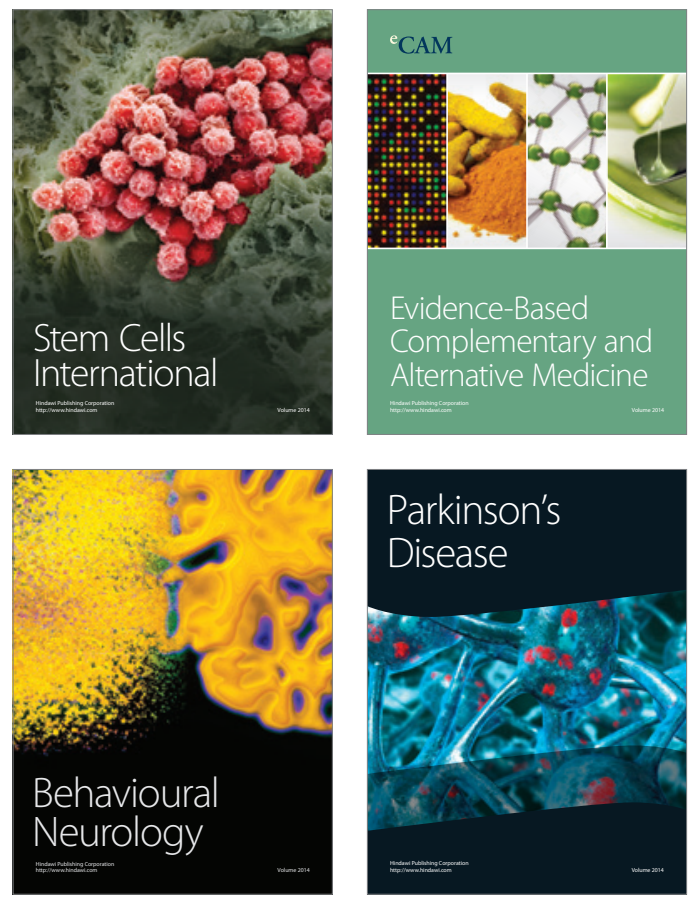


Disease Markers
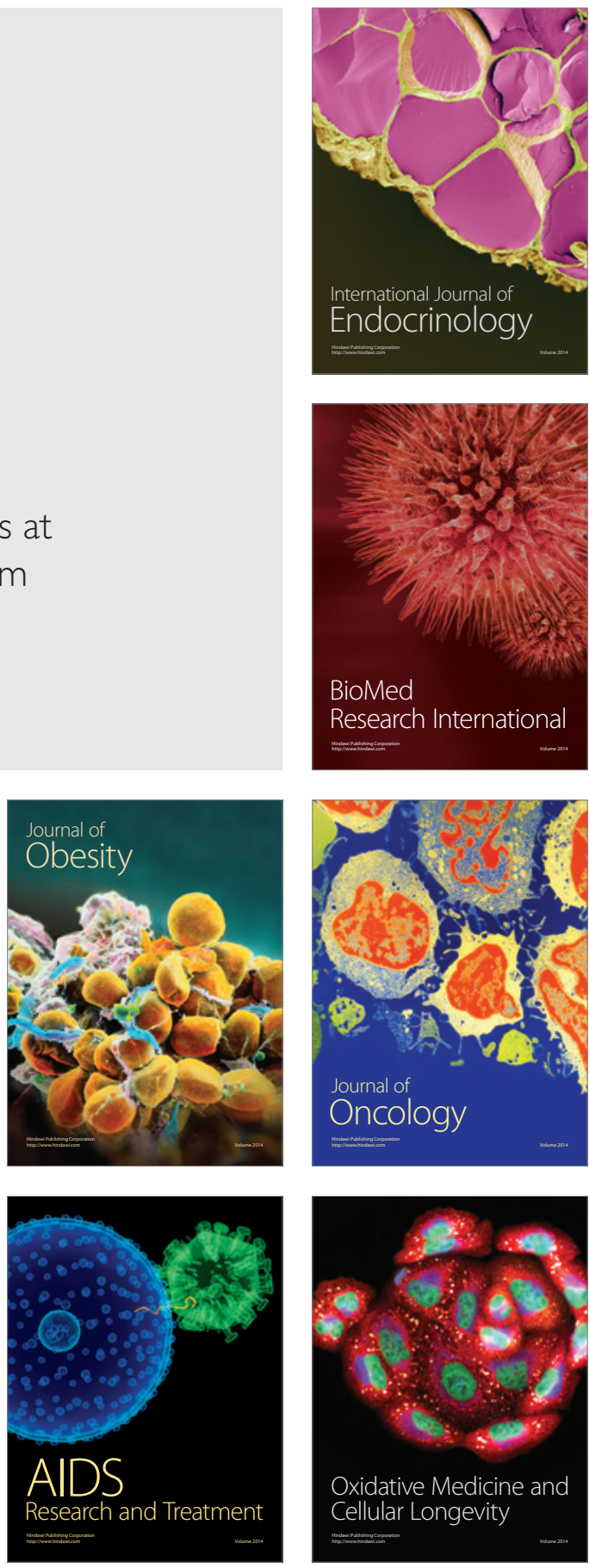